Revista Destaques Acadêmicos, Lajeado, v. 9, n. 4, 2017. ISSN 2176-3070

DOI: http://dx.doi.org/10.22410/issn.2176-3070.v9i4a2017.1500

www.univates.br/revistas

\title{
LIGAS DE ZINCO-ALUMÍNIO HIPOEUTÉTICAS: EFEITO DO COBRE E TRATAMENTO TÉRMICO NA MICROESTRUTURA
}

\author{
Daniel Saraiva da Silva ${ }^{1}$, Eleani Maria da Costa ${ }^{2}$
}

\begin{abstract}
Resumo: Neste trabalho estuda-se a influência da adição de cobre e de tratamento térmico na microestrutura da liga Zamac 8 comercial (ZnAl4Cu2,6Mg0,5). Para tal, duas ligas foram fundidas, a liga zamac 8 e a liga zamac 8 com adição de $8 \%$ em peso de cobre, sendo que a solidificação foi acompanhada por análise térmica. $\mathrm{O}$ tratamento térmico foi realizado em duas condições: a $150{ }^{\circ} \mathrm{C} 143 \mathrm{~h}$ e a $300^{\circ} \mathrm{C}$ por $94 \mathrm{~h}$. A caracterização das ligas antes e após a realização do tratamento térmico foram realizadas por microscopia eletrônica de varredura e mapeamento por EDS (Energy Dispersive X-Ray Spectroscopy) e por medidas de dureza Brinell. A adição de cobre levou a um aumento no intervalo de solidificação da liga Zamac 8 comercial e alterou o tempo da formação de cada fase/ microconstituinte, levando à variação entre as quantidades relativas de cada fase ou microconstituinte. Os tratamentos térmicos alteraram a microestrutura, tanto da liga comercial quanto da liga modificada pela adição de cobre. Para a liga Zamac 8 comercial o tratamento térmico realizado a $300{ }^{\circ} \mathrm{C}$ por $94 \mathrm{~h}$ foi o que promoveu a diminuição partículas da fase $\varepsilon$ presentes nas dendritas da fase, enquanto que para a liga Zamac 8 com adição de Cobre foi o tratamento térmico realizado a $150^{\circ} \mathrm{C}$ por $143 \mathrm{~h}$. No entanto, o mapeamento por EDS mostra que há cobre em maior concentração na fase primária independente da temperatura e tempo de tratamento térmico, indicando que pode ter havido transformação da fase metaestável $\varepsilon$ na fase estável $\tau$, que também contém cobre. Não foi verificado alteração significativa na dureza do material após tratamento térmico, exceto na liga comercial Zamac 8 tratada termicamente a $150{ }^{\circ} \mathrm{C}$ por 94 horas, esta alteração pode ser explicada pela microestrutura, onde o percentual da estrutura eutética presente é baixo.
\end{abstract}

Palavras-chave: Liga de Zn-Al. Tratamento térmico. Efeito do cobre.

1 Engenheiro Mecânico, Pontifícia Universidade Católica do Rio Grande do Sul (PUCRS).

2 Doutora, Química - Pontifícia Universidade Católica do Rio Grande do Sul (PUCRS). 


\section{INTRODUÇÃO}

A ligas de zinco tem amplas aplicações na engenharia e possuem propriedades interessantes para processos de fundição, como boa fluidez, baixa temperatura de fusão, e não é necessário o uso de fluxo de gás ou atmosferas protetoras. No caso de ligas de $\mathrm{Zn}$-Al há dois principais tipos de famílias de ligas, as hipereutéticas com a composição contendo 5,1\% ou mais de peso de $\mathrm{Al}$ e ligas hipoeutéticas com 5,1\% em peso de $\mathrm{Al}$ ou menos (El-Kahir, 2004). O $\mathrm{Al}$ confere uma maior fluidez, refina os grãos e melhora a resistência mecânica (Prasad, 2000).

Cobre e magnésio são frequentemente adicionados nas ligas de $\mathrm{Zn}$ Al para obtenção de melhores propriedades mecânicas e aumenta resistência à corrosão (Prasad, 2003; Costa, 2009). Estes elementos podem alterar as propriedades das ligas de $\mathrm{Zn}$-Al visto que alteram as temperaturas de mudança de fase, promovendo ainda a precipitação de novas fases. Além do cobre e magnésio, outros elementos de liga têm sido adicionados às ligas de $\mathrm{Zn}$ - $\mathrm{Al}$ com a finalidade de melhorar as propriedades mecânicas, propriedades tribológicas e de resistência à corrosão (El-Kahir, 2004).

As principais ligas à base de zinco usadas para fundição são classificadas em dois grupos, o das ligas chamadas Zamac a base de $\mathrm{Zn}, \mathrm{Al}, \mathrm{Cu}$ e $\mathrm{Mg}$ e o das ligas ZA (ligas de Zn-Al). As ligas Zamac são ligas a base de Zn-Al hipoeutéticas, enquanto as ligas ZA são ligas a base Zn-Al hipereutéticas. (ASM Handbook, Vol. 15, 1992).

Embora o cobre tenha influência importante nas propriedades das ligas $\mathrm{Zn}-\mathrm{Al}$, a presença da fase metaestável $\varepsilon\left(\mathrm{CuZn}_{4^{\prime}}\right.$ composto intermetálico) formase quando o teor de cobre é superior a 1\%, e se grandes concentrações de cobre estiver presente na liga a precipitação desta fase poderá causar instabilidade dimensional da liga ao longo do tempo, devido a transformação desta fase metaestável na fase estável $\tau$ (Dorantes-Rosales, 1999; Prasad, 2000; Costa 2009; Savaskan e Hekimoglu, 2014). A formação da fase metaestável CuZn ${ }_{4}$ e as transformações que acontecem por tratamentos térmicos tem sido bastante estudada para as ligas de $\mathrm{Zn}$-Al eutetóides e hipereutéticas (Dorantes-Rosales, 1999; Zhu e Lee, 2000; Prasad, 2000), mas há pouco relato na literatura sobre essas transformações para as ligas Zn-Al hipoeutéticas.

Sabe-se que o estudo da formação das microestruturas durante o processo de solidificação de materiais e após tratamento térmico é essencial para aperfeiçoamento e obtenção de melhores propriedades das ligas metálicas. Neste cenário, o principal objetivo deste trabalho é estudar o efeito da adição de cobre e do tratamento térmico na microestrutura de uma liga quaternária hipoeutética de $\mathrm{Zn}$-Al (Zamac 8). Estes efeitos foram estudados através da caracterização microestrutural da liga antes e após o tratamento térmico obtidas pela análise das curvas de solidificação, por microscopia óptica e microscopia eletrônica de varredura (MEV). A identificação da composição química das 
fases presentes foi feita por mapeamento por EDS (Energy Dispersive X-Ray Spectroscopy). Além disto, também foi efetuada a caracterização de dureza das ligas antes e após tratamento térmico pela técnica de dureza Brinell,

\section{MATERIAIS E MÉTODOS}

A fundição e os tratamentos térmicos das ligas de Zinco foram realizados no Laboratório de Materiais da Faculdade de Engenharia da Pontifícia Universidade Católica do Rio Grande do Sul (PUCRS).

\subsection{FUSÃO DAS LIGAS}

Duas ligas hipoeutéticas de Zinco-Alumínio foram estudadas, a liga hipoeutética comercial Zamac 8, desenvolvida pela Votorantim Metais S.A. para o mercado nacional para fundição centrifugada, cuja composição química é apresentada na Tabela 1 e a liga Zamac 8 com adição de $8 \%$ de $\mathrm{Cu}$. A liga Zamac 8 tem composição química similar à liga Zamac 2 em termos de teor de $\mathrm{Al} \mathrm{e} \mathrm{Cu}$, porém tem um acréscimo na quantidade de magnésio em relação à liga Zamac 2, enquanto na liga Zamac 2 padronizada o teor de $\mathrm{Mg}$ pode variar de 0,02 a $0,05 \%$ em peso na liga Zamac 8 este elemento pode variar de 0,45 a $0,65 \%$ em peso.

Tabela 1 - Composição química da liga comercial Zamac ZAP obtida por espectroscopia de emissão óptica.

\begin{tabular}{c|c|c|c|c|c|c|c|c}
\hline & $\mathbf{A l}$ & $\mathbf{C u}$ & $\mathbf{M g}$ & $\mathbf{F e}$ & $\mathbf{P b}$ & $\mathbf{C d}$ & $\mathbf{S n}$ & $\mathrm{Zn}$ \\
\hline Mínimo & $3,500 \%$ & $2,000 \%$ & $0,450 \%$ & $0,000 \%$ & $0,000 \%$ & $0,000 \%$ & $0,000 \%$ & $92,403 \%$ \\
\hline $\begin{array}{c}\text { Encontra- } \\
\text { do }\end{array}$ & $\mathbf{4 , 1 3 4 \%}$ & $\mathbf{2 , 5 7 6} \%$ & $\mathbf{0 , 4 9 0} \%$ & $\mathbf{0 , 0 0 9} \%$ & $\mathbf{0 , 0 0 1} \%$ & $\mathbf{0 , 0 0 0} \%$ & $\mathbf{0 , 0 0 0} \%$ & $\mathbf{9 3 , 4 2 4 \%}$ \\
\hline Máximo & $4,200 \%$ & $2,700 \%$ & $0,650 \%$ & $0,035 \%$ & $0,005 \%$ & $0,003 \%$ & $0,002 \%$ & $94,500 \%$ \\
\hline
\end{tabular}

Fonte: Zinco ligas (2015).

Foi utilizado para fundição da liga um forno resistivo do fabricante Sanchis, modelo NFF 20, conforme mostrado na Figura 1. A temperatura de vazamento foi de aproximadamente $500{ }^{\circ} \mathrm{C}$ para a liga sem adição de cobre e $600{ }^{\circ} \mathrm{C}$ para a liga com adição de cobre. 
Figura 1 - Forno resistivo utilizado para fusão das diferentes ligas de zinco.

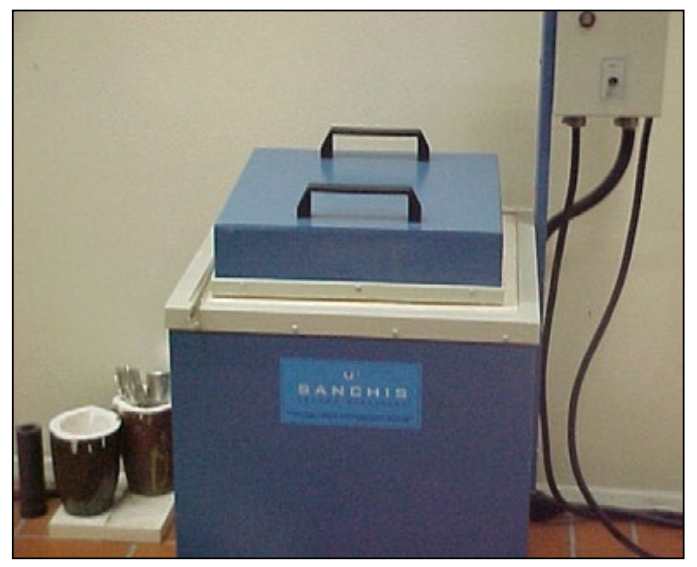

Fonte: Autor próprio.

Informações sobre as características de solidificação das ligas foram obtidas por análise térmica pelo método CA-CCA (Computer-Aided Cooling Curve Analysis). A análise da curva de resfriamento assistido por computador é um método de baixo custo para analise térmica, podendo ser utilizado para prever a microestrutura presente no material, a cinética de solidificação e o calor latente liberado durante o processo de solidificação. Nesta técnica o material fundido é monitorado durante o processo de solidificação. Como resultado tem-se a curva de resfriamento do metal líquido até a temperatura ambiente (Costa, 2009). Para tal, a liga fundida foi vazada em um molde tipo tectip que possui um termopar instalado na base (ver Figura 2), o qual é ligado a um sistema de aquisição de dados.

Figura 2 - Molde (tectip) utilizado para solidificação das diferentes ligas.

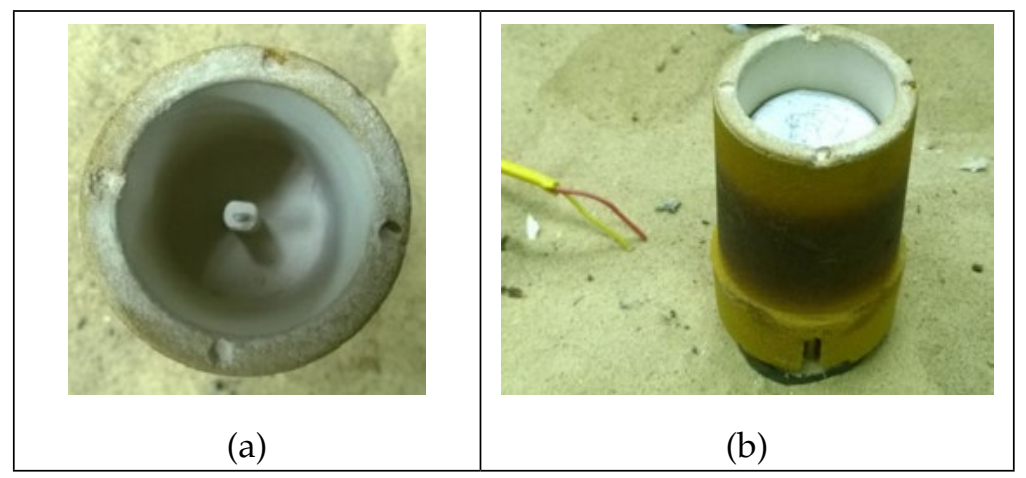

Fonte - Autor próprio 


\subsection{TRATAMENTOS TÉRMICOS}

Para fins de estudo da estabilização ou transformação da fase metaestável $\mathrm{CuZn}_{4}$ foi realizado tratamento térmico das ligas. Estudos anteriores identificaram a transformação da fase metaestável $\varepsilon$ na fase estável $\tau$ durante o tratamento térmico de solubilização a $150^{\circ} \mathrm{C}$ por 145 horas. (Zhu et al., 2001). Esta transformação de fases tem sido identificada em tratamentos térmicos abaixo de $250^{\circ} \mathrm{C}$. (Dorantes-Rosales, 1999). Baseados nestes estudos dois diferentes tratamentos térmicos foram realizados, conforme especificados abaixo.

- Tratamento Térmico a $150^{\circ} \mathrm{C}$ por 143 horas;

- Tratamento Térmico a $300^{\circ} \mathrm{C}$ por 94 horas.

Para a realização dos tratamentos térmicos, os lingotes obtidos foram cortados em quatro discos finos de aproximadamente $10 \mathrm{~mm}$ de espessura. As amostras foram resfriadas dentro do forno.

\subsection{CARACTERIZAÇÃO MICROESTRUTURAL E DETERMINAÇÃO DA DUREZA}

As características microestruturais das ligas antes e após tratamento térmico foram obtidas pela análise das curvas de solidificação, por microscopia óptica e microscopia eletrônica de varredura-MEV. A identificação da composição química das fases presentes foi feita por mapeamento por EDS (Energy Dispersive X-Ray Spectroscopy).

A dureza das ligas antes e após tratamento térmico foi determinada pela técnica de dureza Brinell, conforme norma ASTM E10-15 (2015), usando esfera de $5 \mathrm{~mm}$ e carga de $250 \mathrm{kgf}(2451,66 \mathrm{~N})$. Os resultados são apresentados como a média de três medidas.

\section{RESULTADOS E DISCUSSÃO}

\subsection{CURVAS DE SOLIDIFICAÇÃO}

A Figura 3 mostra as curvas de resfriamento da liga Zamac 8 comercial (ZnAl4Cu2,6Mg0,5) e da liga Zamac 8 modificada pela adição de $8 \%$ em Cobre. A liga Zamac 8 comercial $(\mathrm{ZnAl} 4 \mathrm{Cu} 2,6 \mathrm{Mg} 0,5)$ apresenta um intervalo de solidificação de $385^{\circ} \mathrm{C}$ a $339^{\circ} \mathrm{C}\left(\Delta \mathrm{T}=46^{\circ} \mathrm{C}\right)$, enquanto que na Zamac 8 modificada pela adição de $8 \%$ de $\mathrm{Cu}$ o intervalo de solidificação foi muito maior, de $518^{\circ} \mathrm{C}$ a $339^{\circ} \mathrm{C}\left(\Delta \mathrm{T}=179^{\circ} \mathrm{C}\right)$. Costa et al. (2009) encontram um intervalo de solidificação muito similar ao deste trabalho para a liga comercial Zamac 8 , de $388^{\circ} \mathrm{C}$ a $339^{\circ} \mathrm{C}$ $\left(\Delta \mathrm{T}=49^{\circ} \mathrm{C}\right)$.

Na curva de resfriamento há indicação de formação de pelos menos três fases e/ou microconstituintes (indicadas por flechas na Figura 10), 
independente do teor de cobre presente. Observa-se ainda que o tempo da formação de cada fase/microconstituinte depende da quantidade de cobre na liga, como consequência disto ocorre uma variação entre as quantidades relativas de cada fase ou microconstituinte presente no material, modificando suas propriedades. Quando comparadas, a formação das dendritas primárias ocorre por um período maior na liga modificada com adição de cobre. Este fato está de acordo com a microestrutura com maior presença de fase primária na liga modificada que na liga comercial, como será mostrado mais adiante.

Figura 3 - Curvas de resfriamento da liga Zamac 8 comercial (ZnAl4Cu2,6Mg0,5) e da liga Zamac 8 modificada pela adição de $8 \%$ em Cobre.

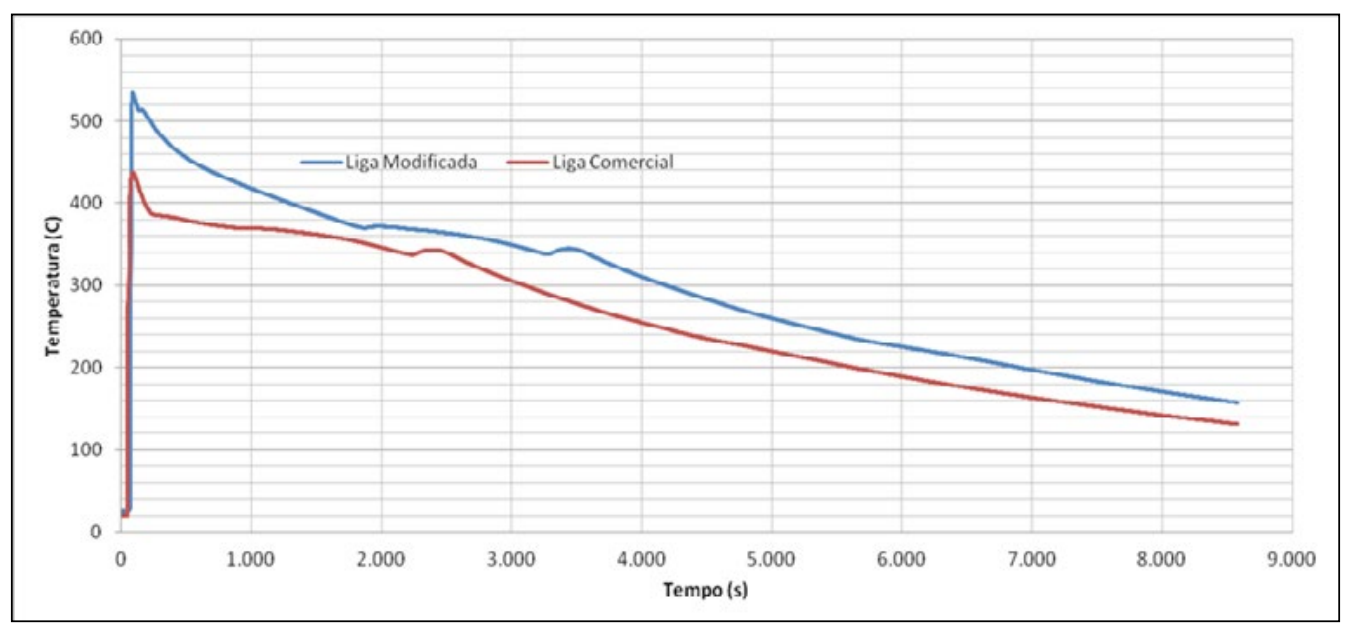

\subsection{MICROESTRUTURA DAS LIGAS BRUTA DE FUSÃO}

As Figuras 4 e 6 mostram imagens de MEV da microestrutura das ligas Zamac 8 comercial e Zamac 8 modificada com adição de $8 \%$ de cobre no estado bruto de fusão, respectivamente.

A microestrutura da liga comercial (FIGURA 4) assim como da liga Zamac 8 modificada (FIGURA 6) são constituídas de dendritas da fase primária $\eta$, de uma estrutura eutetóide constituída de lamelas de $\alpha+\eta$ e de uma estrutura eutética na região interdendrítica que é composta da fase $\eta$ mais o eutetóide. Observa-se também a presença de partículas da fase $\varepsilon\left(\mathrm{CuZn}_{4}\right)$ no interior da fase primária (pontos escuros).

Observa-se que com aumento do teor de cobre (liga modificada) houve a diminuição na quantidade relativa da estrutura eutética e da estrutura eutetóide, levando a um aumento na quantidade relativa de dendritas primárias da fase $\eta$. A fase primária e a estrutura eutétóide tem morfologia mais globular na liga comercial em relação à liga modificada com adição cobre. 
As Figuras 5 e 7 mostram os mapeamentos dos elementos $\mathrm{Zn}, \mathrm{Cu}$ e $\mathrm{Al}$ realizados por EDS nas ligas Zamac 8 comercial e Zamac 8 modificada com adição de $8 \%$ de cobre no estado bruto de fusão, respectivamente. Pode-se observar na liga Zamac 8 comercial que a estrutura eutetóide é rica em $\mathrm{Al}$ enquanto a fase primária é rica em Zn. O mesmo acontece com a liga Zamac 8 modificada, ou seja, a fase eutetóide é rica em Al e este elemento também está presente na estrutura eutética em ambas as ligas. Para a liga modificada, pode-se observar que o $\mathrm{Cu}$ se concentra nas dendritas da fase primária. No mapeamento por EDS o $\mathrm{Cu}$ não foi detectado na liga Zamac 8 comercial. No entanto, o cobre foi detectado na fase primária quando realizado EDS em região selecionada.

Figura 4 - Imagens de MEV no modo BSE da liga Zamac 8 comercial (ZnAl4Cu2,6Mg0,5) no estado bruto de fusão

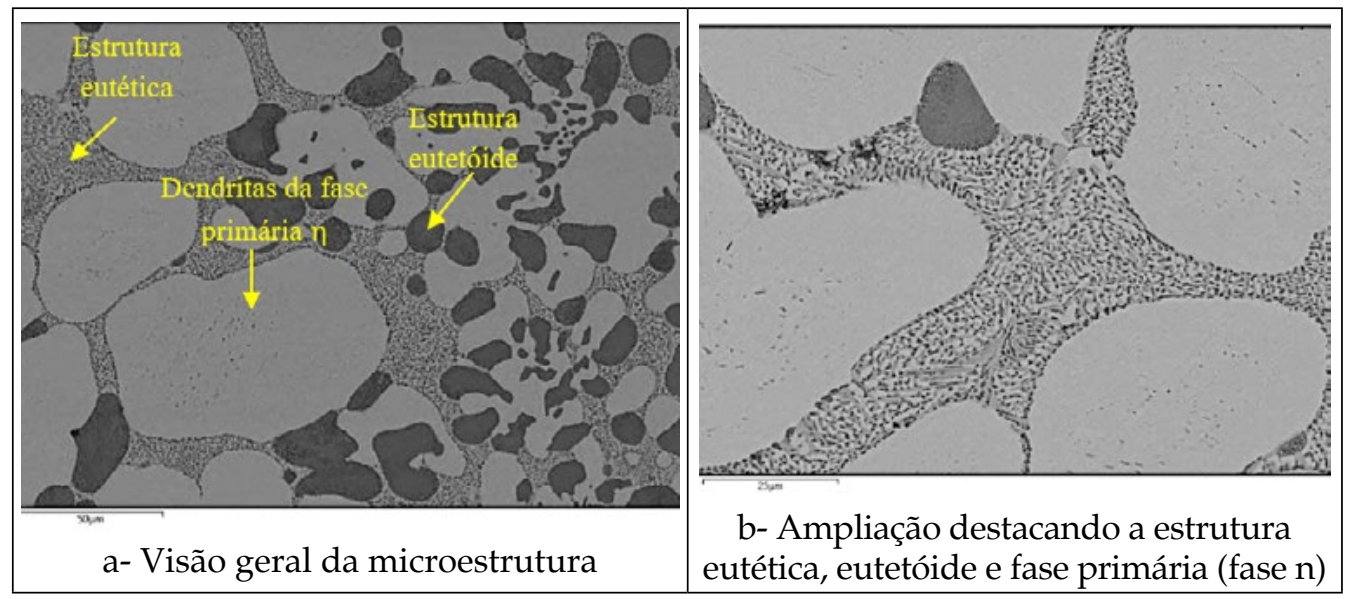




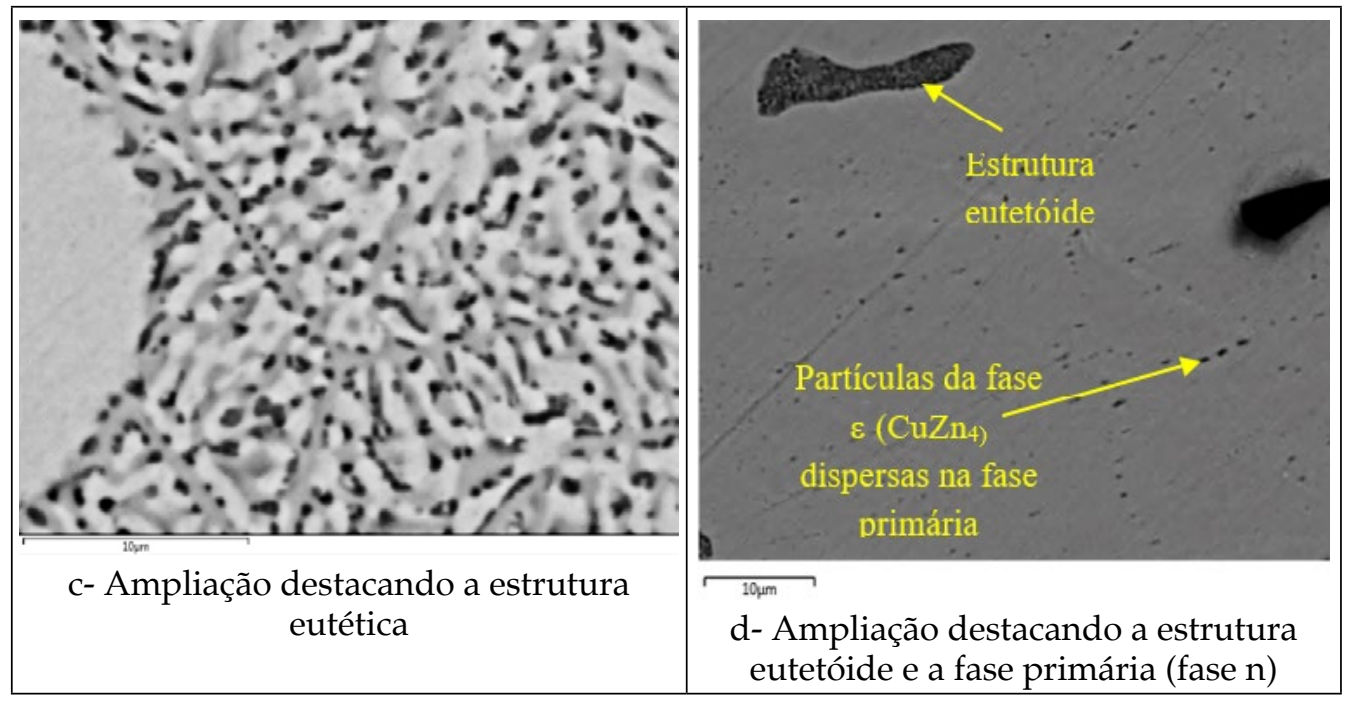

Figura 5 - Mapeamento por EDS dos elementos Al e Zn na liga Zamac 8 comercial (ZnAl4Cu2,6Mg0,5) no estado bruto de fusão.

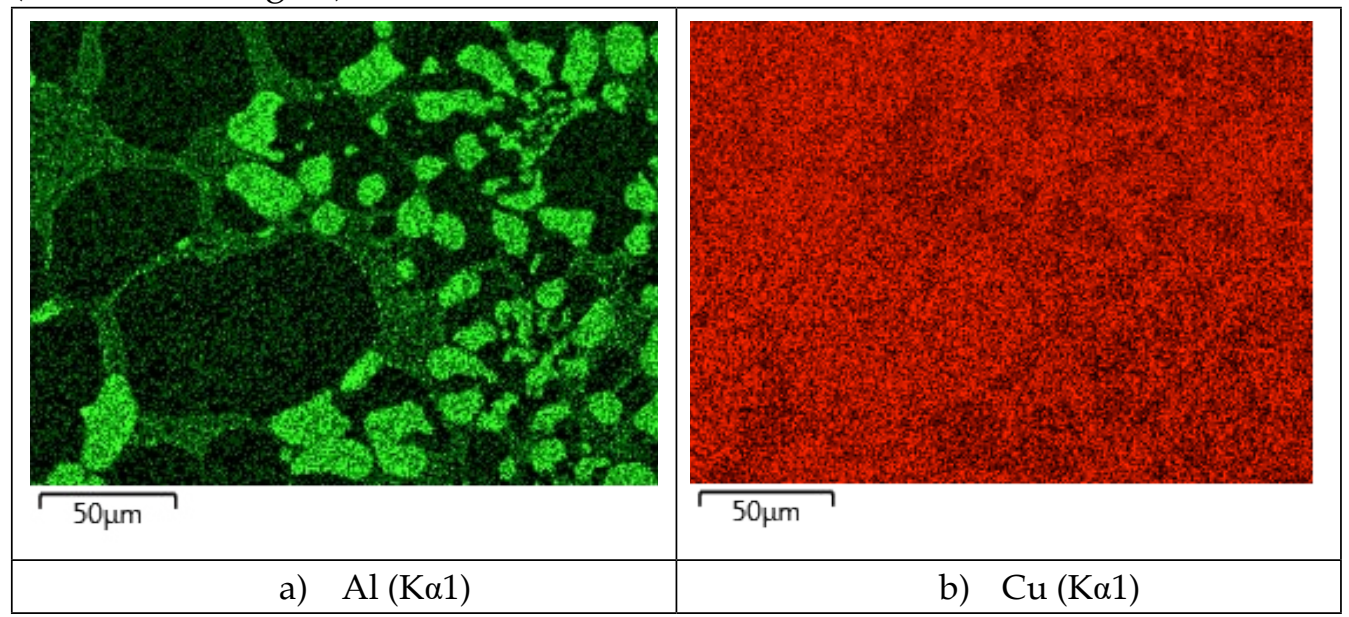


Figura 6 - Imagens de MEV no modo BSE da liga Zamac 8 modificada com adição de $8 \%$ de cobre no estado bruto de fusão

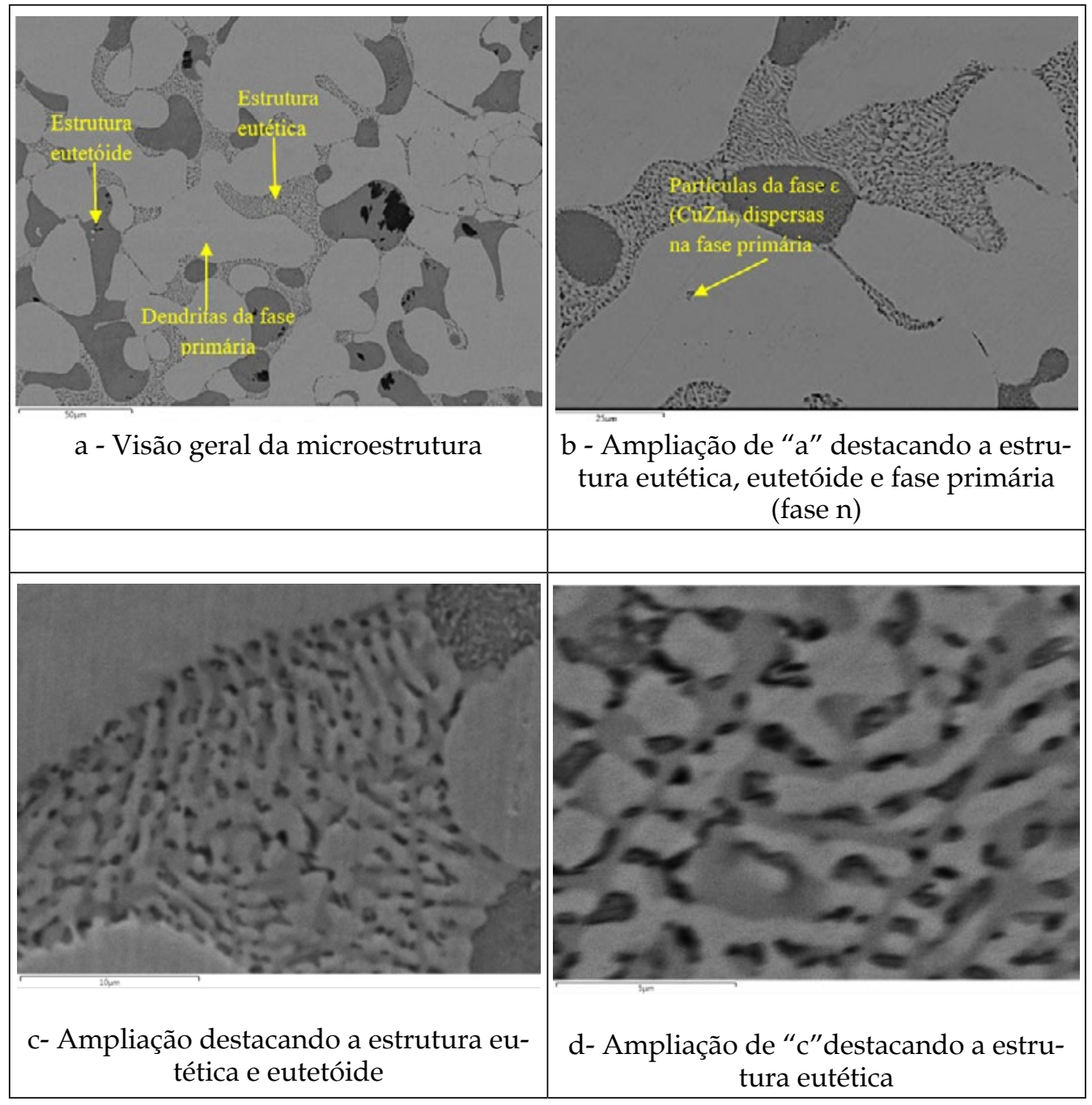


Figura 7- Mapeamento por EDS dos elementos $\mathrm{Al}, \mathrm{Cu}$ e $\mathrm{Zn}$ na liga Zamac 8 modificada pela adição de $8 \%$ de cobre no estado bruto de fusão

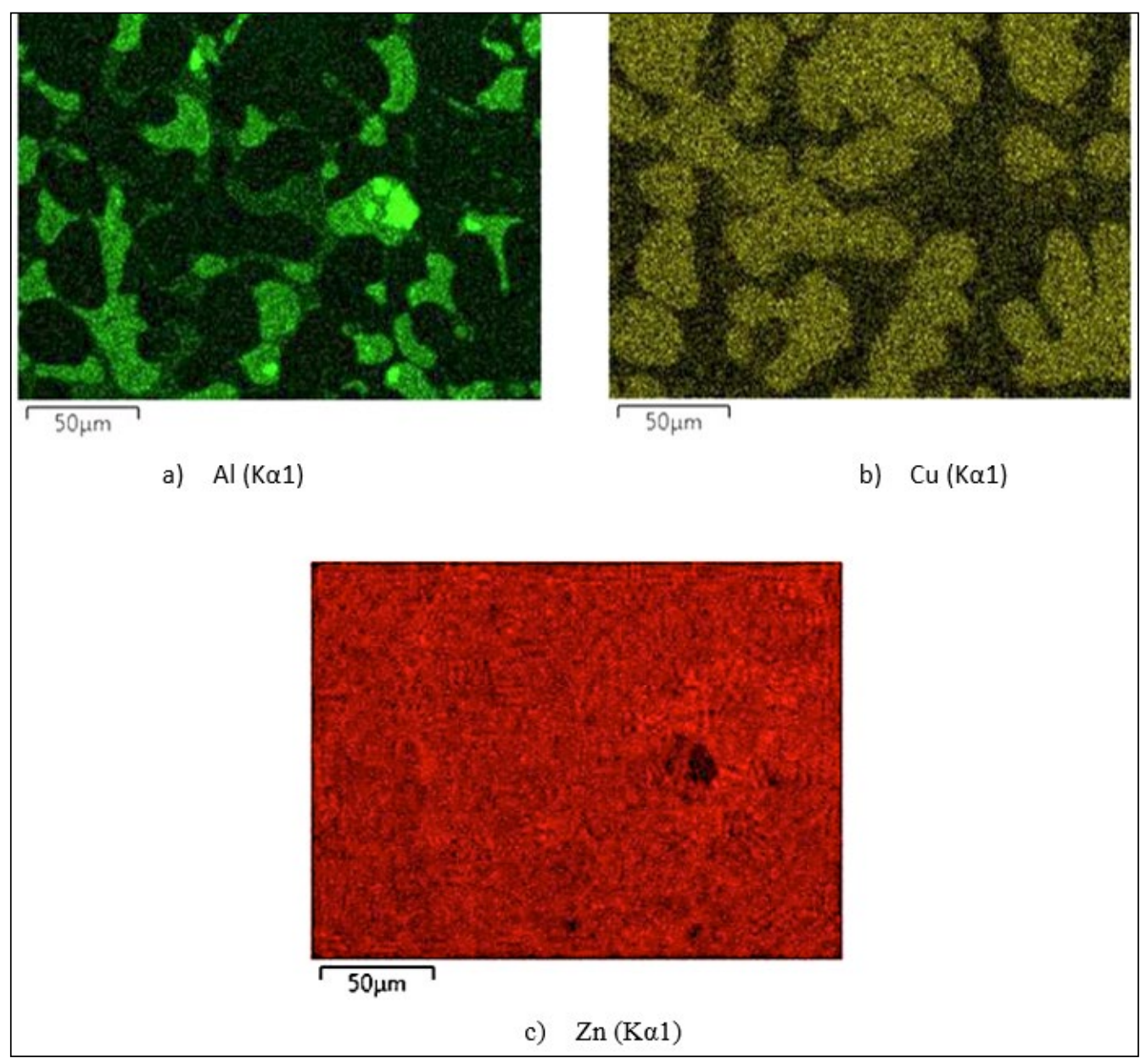

\subsection{MICROESTRUTURA DAS LIGAS APÓS TRATAMENTO TÉRMICO}

As Figuras 8 e 9 mostram imagens de MEV da microestrutura das ligas Zamac 8 comercial e mapeamento por EDS dos elementos Al e $\mathrm{Zn}$ para os tratamentos térmicos de $150^{\circ} \mathrm{C}$ por $143 \mathrm{~h} \mathrm{e} 300^{\circ} \mathrm{C}$ por $94 \mathrm{~h}$, respectivamente. Em relação à liga bruta de fusão, pode-se o observar que os tratamentos térmicos realizados tanto a $150{ }^{\circ} \mathrm{C}$ quanto a $300^{\circ} \mathrm{C}$ reduziram a quantidade relativa da estrutura eutética. Sendo que pequena quantidade de estrutura eutética resultou após tratamento térmico a $300^{\circ} \mathrm{C}$, como melhor evidenciado na Figura 10. Além disso, uma nova fase contendo cobre se formou (indicada por uma flecha na Figura 10) na região interdendrítica. 
Figura 8 - Imagens de MEV no modo BSE e mapeamento dos elementos $\mathrm{Al}$ e Zn da liga Zamac 8 comercial $(\mathrm{ZnAl} 4 \mathrm{Cu} 2,6 \mathrm{Mg} 0,5)$ após tratamento térmico a $150^{\circ} \mathrm{C}$ por $143 \mathrm{~h}$.

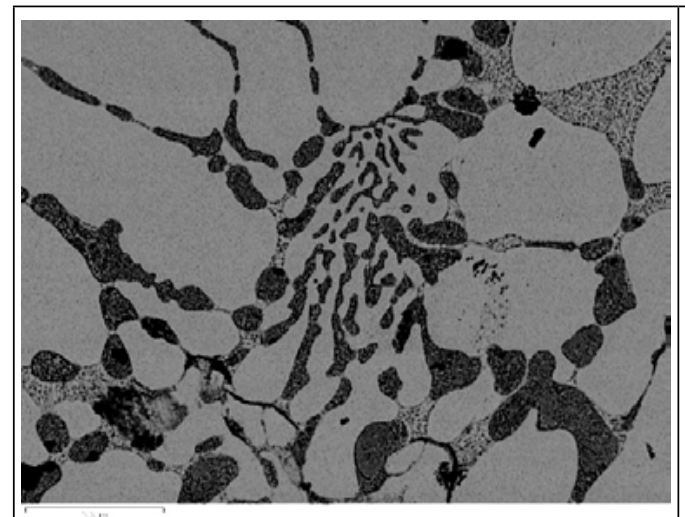

a) Visão geral da microestrutura

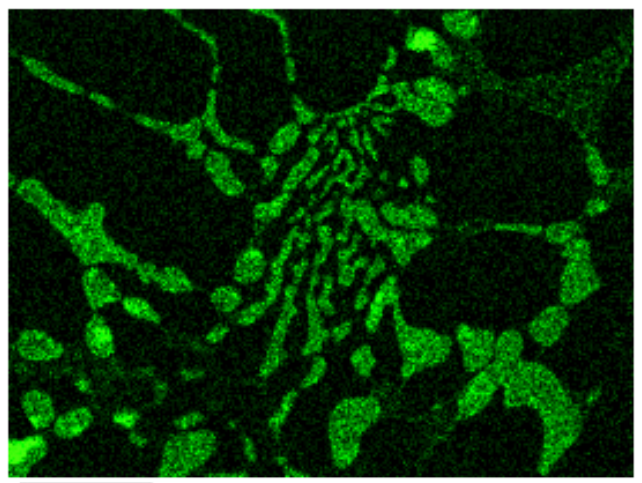

$50 \mu \mathrm{m}$

c) Mapeamento do $\mathrm{Al}(\mathrm{K} \alpha 1)$ em " $\mathrm{a}$ "

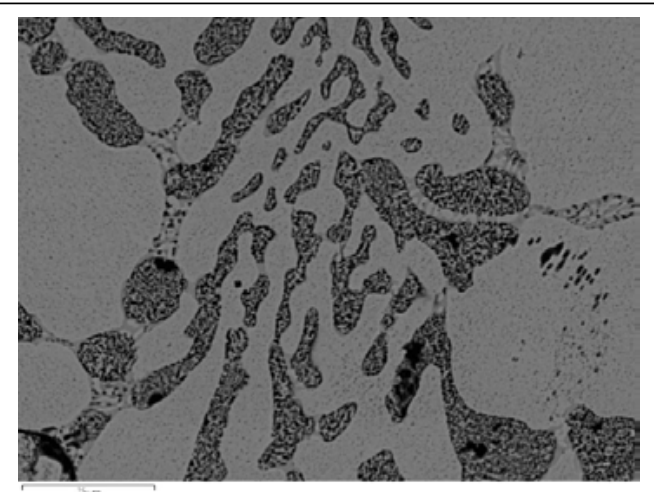

b) Ampliação de "a" destacando a estrutura eutética, eutetóide e fase primária (fase $\eta$ )

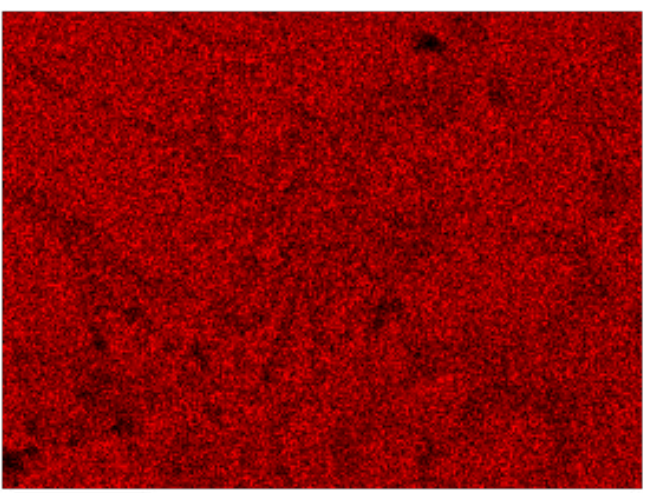

$50 \mu \mathrm{m}$

d) Mapeamento do $\mathrm{Zn}(\mathrm{K} \alpha 1)$ em "a"

Pode-se observar também que na liga tratada a $150{ }^{\circ} \mathrm{C}$ ainda algumas partículas da fase $\varepsilon$ estão presentes nas dendritas da fase primária (FIGURA 8), enquanto que na liga tratada a $300^{\circ} \mathrm{C}$ não (FIGURA 9). 
Figura 9 - Imagens de MEV no modo BSE e mapeamento dos elementos $\mathrm{Al}$ e Zn da liga Zamac 8 comercial $(\mathrm{ZnAl} 4 \mathrm{Cu} 2,6 \mathrm{Mg} 0,5)$ após tratamento térmico a $300^{\circ} \mathrm{C}$ por $94 \mathrm{~h}$.

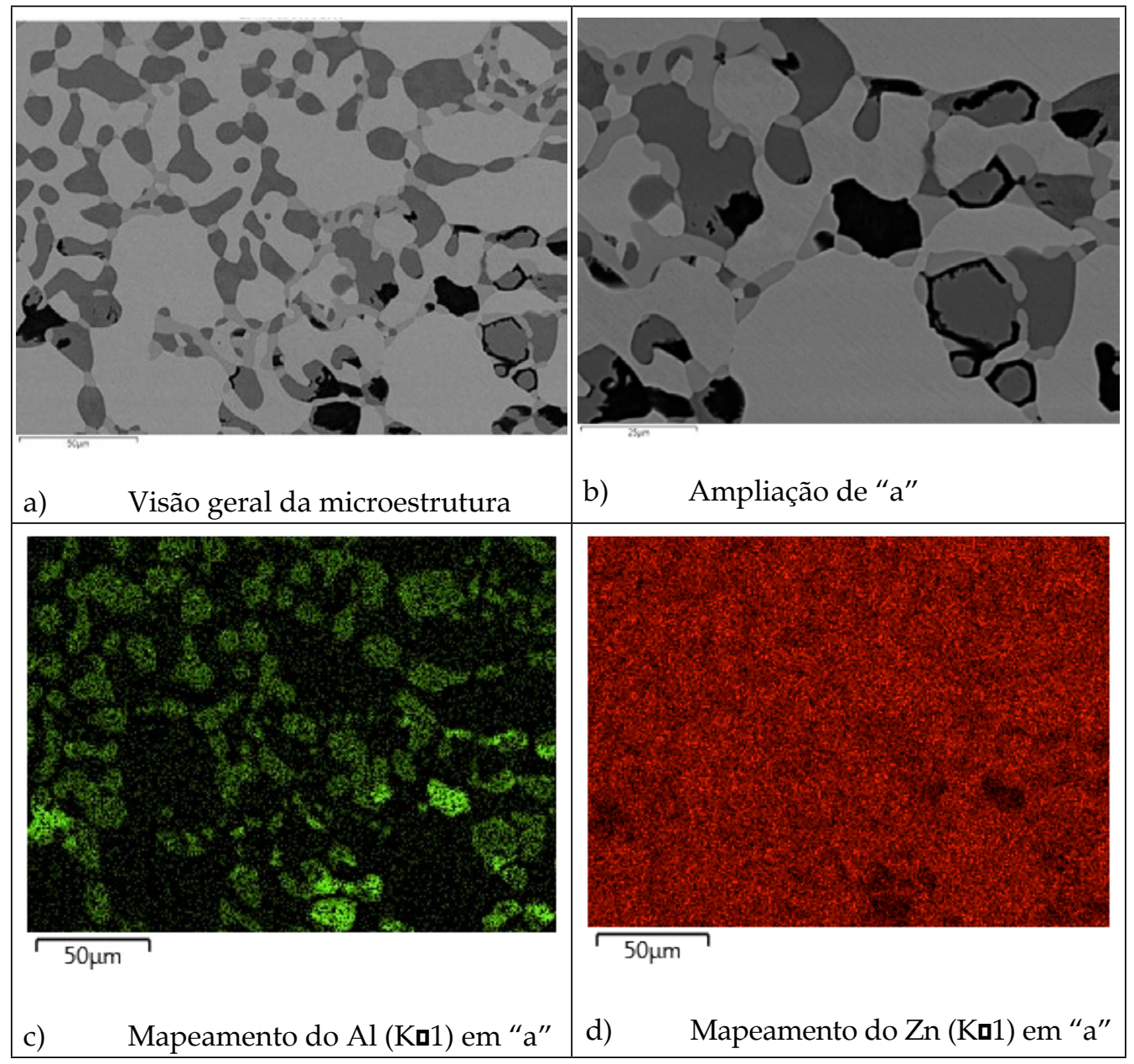


Figura 10 - Imagens de MEV no modo BSE e SE e mapeamento dos elementos $\mathrm{Al}$ e $\mathrm{Zn}$ da liga Zamac 8 comercial (ZnAl4Cu2,6Mg0,5) em diferentes estados. A seta indicada em branco na figura (c) indica a presença de uma nova fase identificada contendo cobre na região interdendrítica

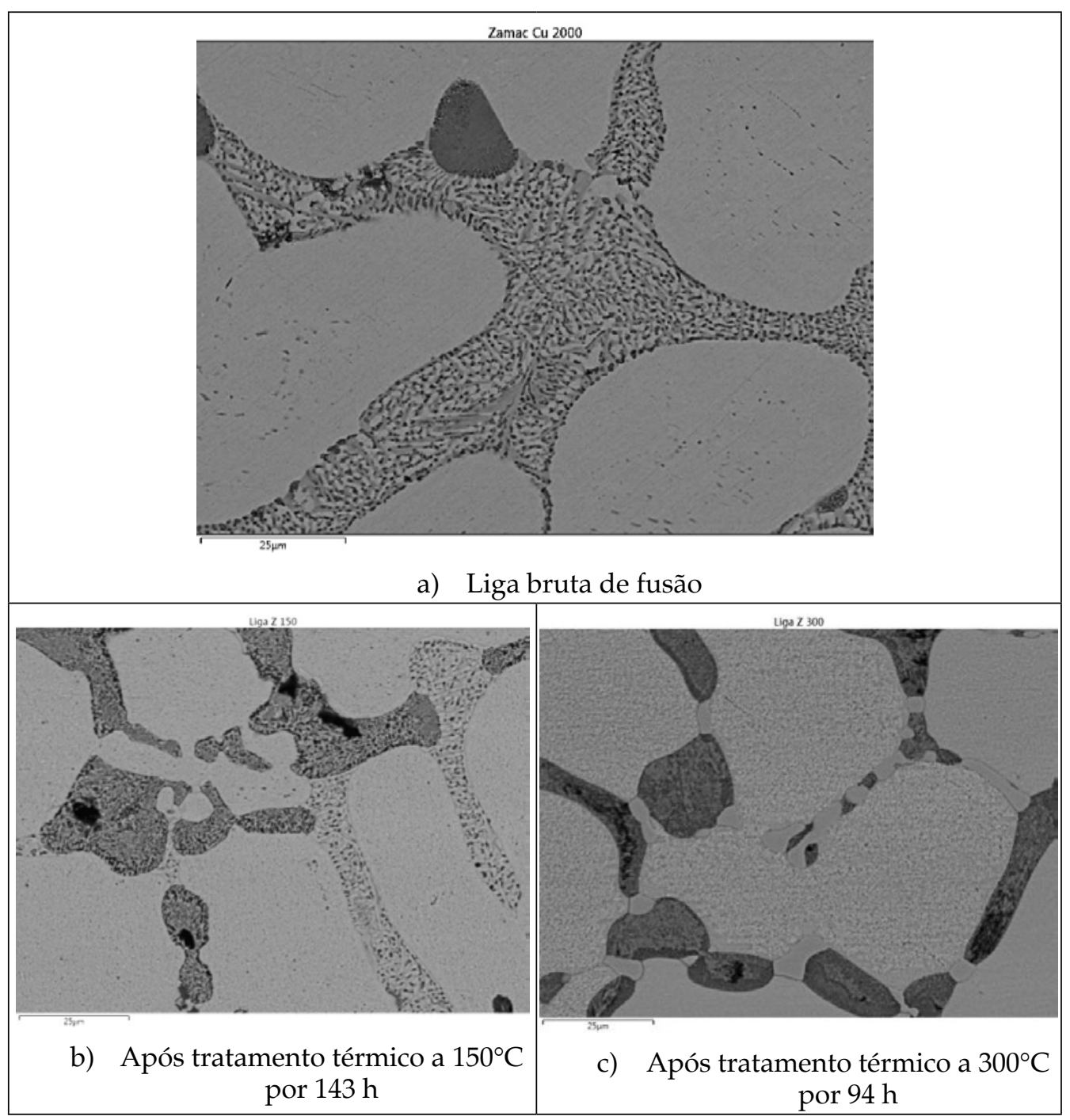




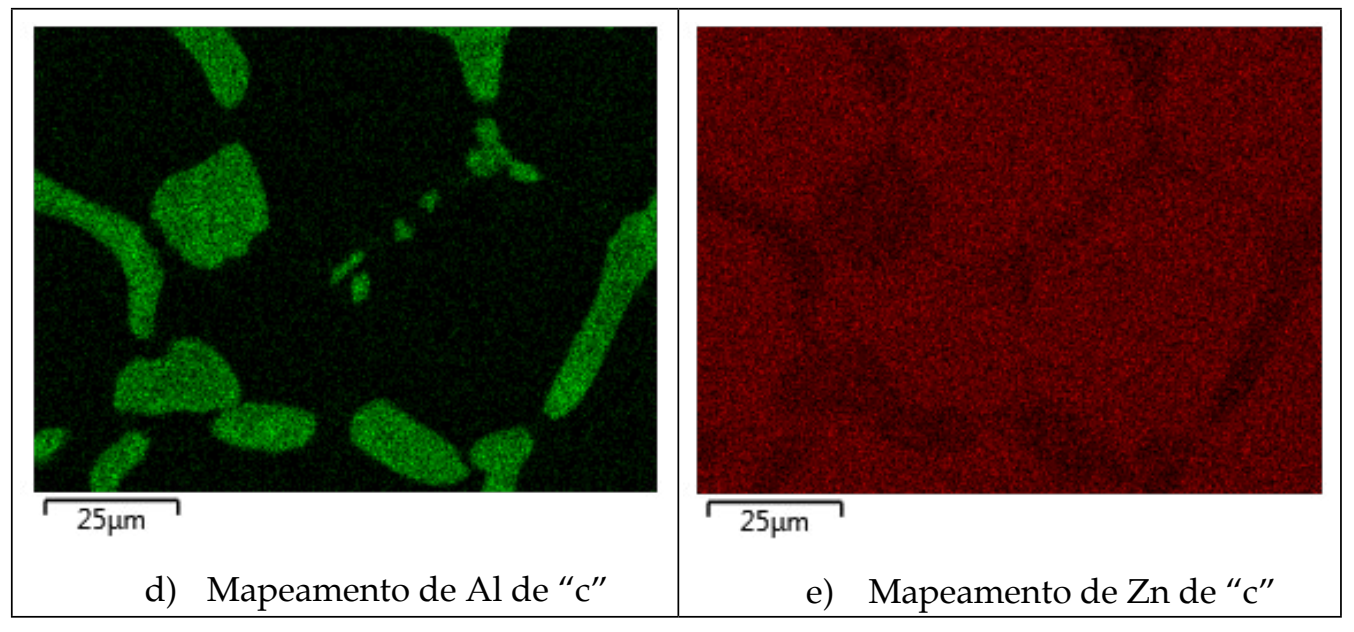

As Figuras 11 e 12 mostram imagens de MEV da microestrutura das ligas Zamac 8 modificada com adição de $8 \%$ de cobre após tratamento térmico a $150{ }^{\circ} \mathrm{C}$ e $300{ }^{\circ} \mathrm{C}$ e mapeamento dos elementos $\mathrm{Al}, \mathrm{Cu}$ e $\mathrm{Zn}$, respectivamente.

Figura 11 - Imagens de MEV no modo BSE e mapeamento dos elementos $\mathrm{Al}, \mathrm{Cu}$ e Zn da liga Zamac 8 modificada pela adição de $8 \%$ de cobre após tratamento térmico a $150^{\circ} \mathrm{C}$ por $143 \mathrm{~h}$

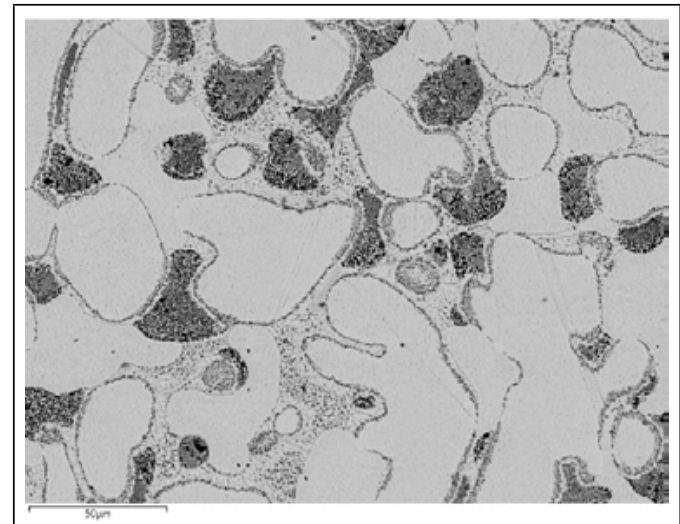

a) Visão geral da microestrutura

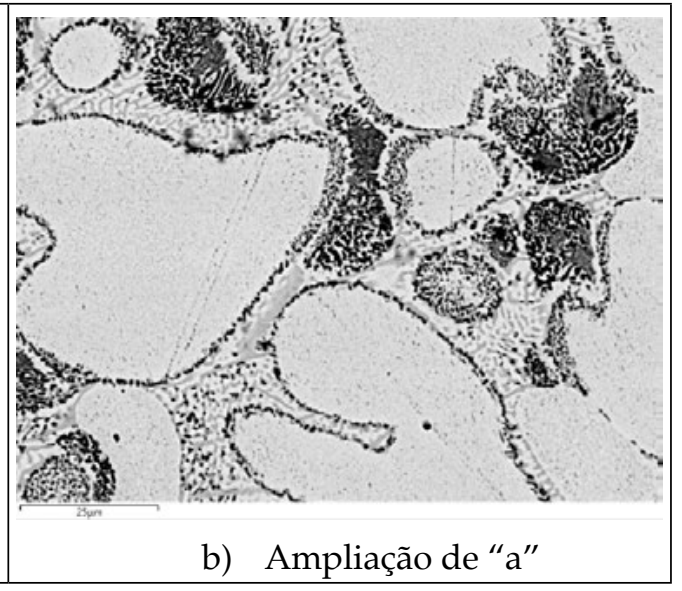




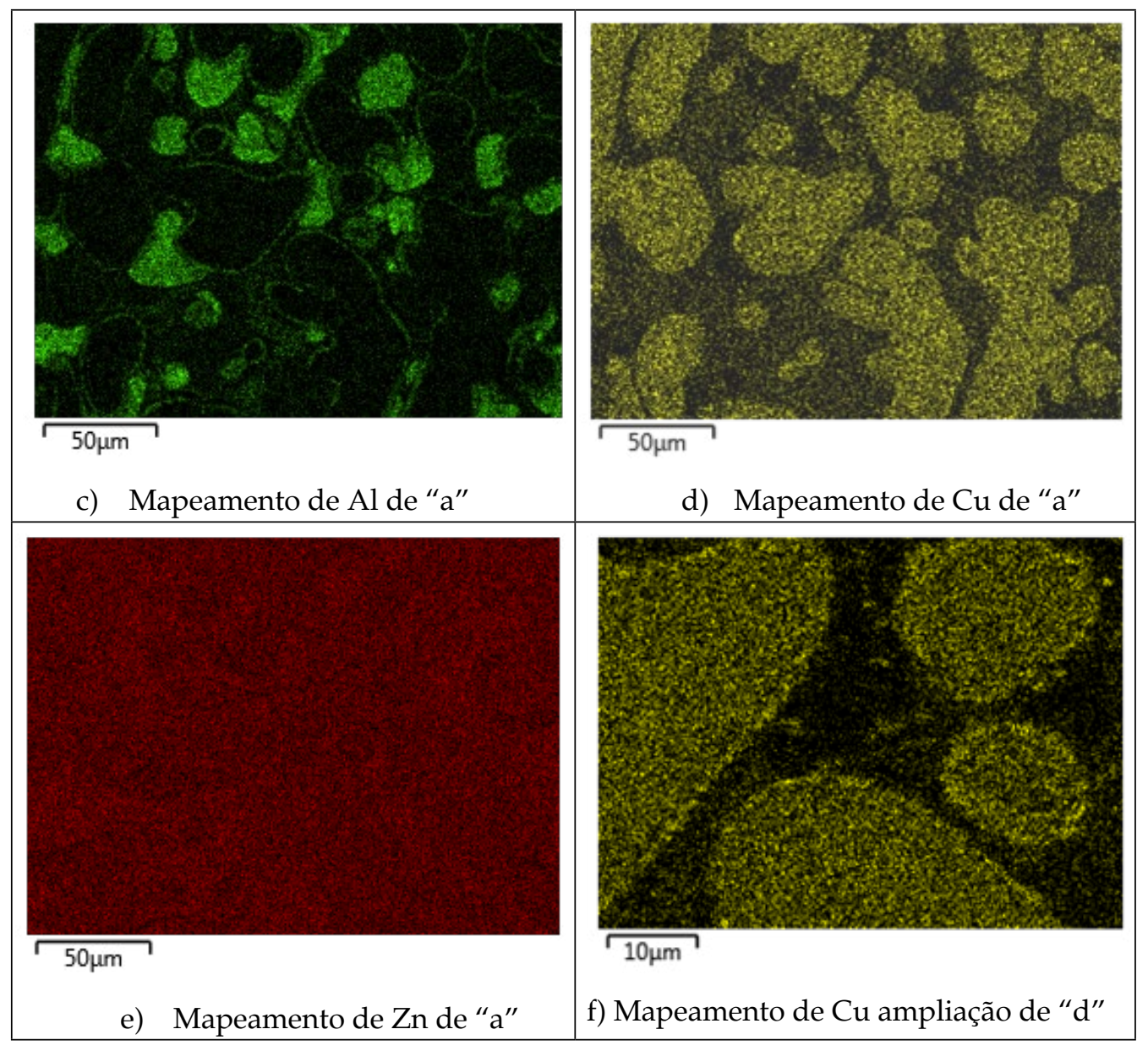


Figura 12 - Imagens de MEV no modo BSE e mapeamento dos elementos $\mathrm{Al}, \mathrm{Cu}$ e Zn da liga Zamac 8 modificada pela adição de $8 \%$ de cobre após tratamento térmico a $300^{\circ} \mathrm{C}$ por $94 \mathrm{~h}$.

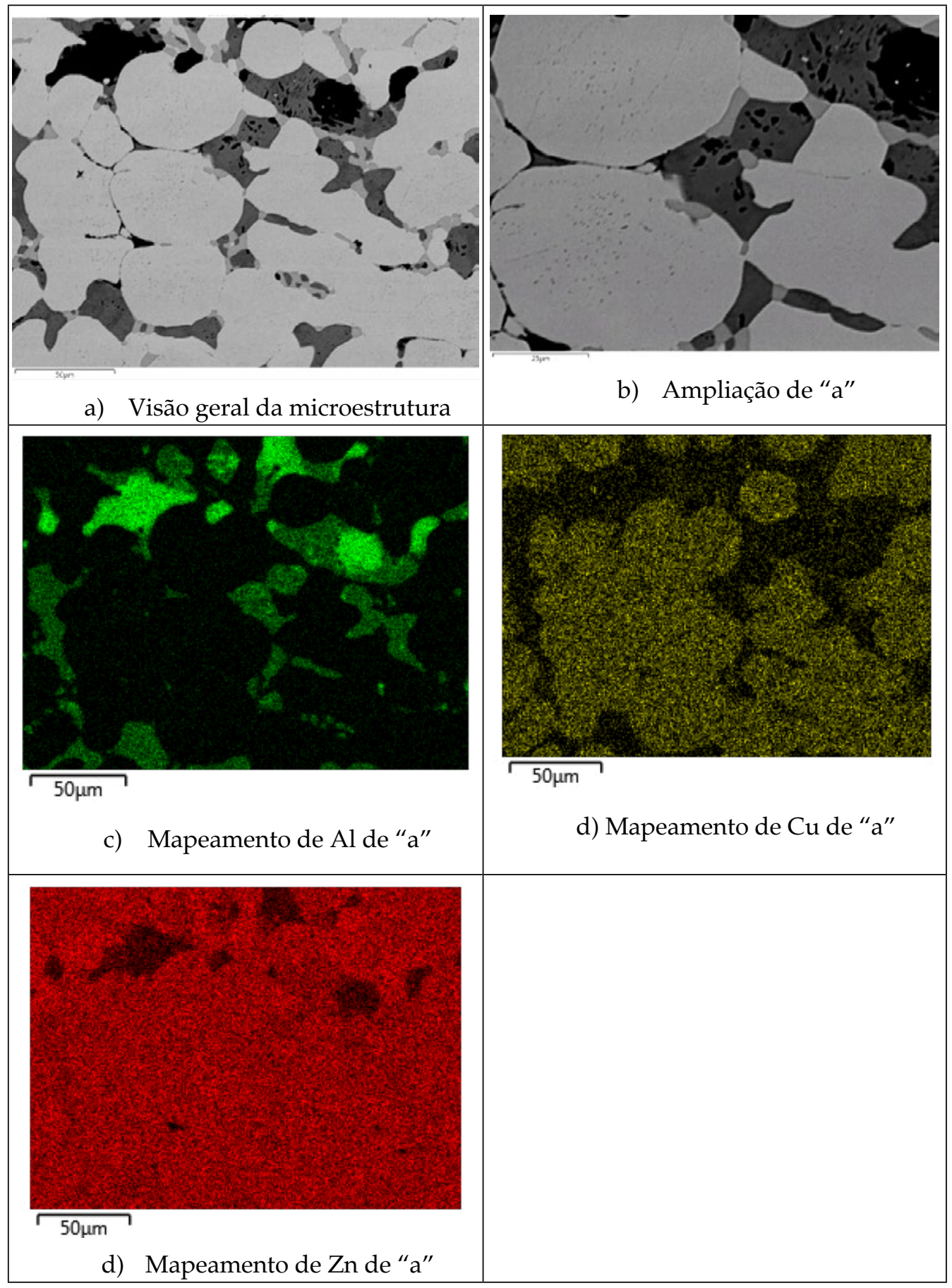


Pode-se observar (FIGURA 11) que na liga Zamac 8 modificada com adição de $8 \%$ de cobre após tratamento térmico a $150{ }^{\circ} \mathrm{C}$ formaram-se partículas nas bordas das dendritas primárias, muito similar ao observado por Zhu et al. (2001) para uma liga ternária de Zn85A4Cu11. Zhu et al. (2001) mostraram que a decomposição da fase $\varepsilon$ leva a precipitação fase $\tau$ nas bordas da estrutura globular da fase primária após tratamento térmico realizado a $150{ }^{\circ} \mathrm{C}$ por 145 h. Já no caso da liga tratamento térmico a $300{ }^{\circ} \mathrm{C}$ (FIGURA 12) observa-se a concentração de partículas nas dendritas da fase primária, indicando que há uma temperatura ideal para realização de tratamento térmico com a finalidade de estabilizar a liga pela transformação da fase $\varepsilon$.

\subsection{DUREZA DAS LIGAS ANTES E APÓS TRATAMENTO TÉRMICO}

A Tabela 2 mostra a dureza Brinell das ligas Zamac 8 comercial e Zamac 8 modificada com adição de $8 \%$ de cobre antes e após tratamento térmico.

Tabela 2 - Dureza Brinell (HB) das ligas Zamac 8 comercial e Zamac 8 modificada com adição de $8 \%$ de cobre no estado bruto de fusão e após tratamento térmico (T.T.)

\begin{tabular}{|c|c|}
\hline Liga/Estado & $\begin{array}{c}\text { Dureza } \\
\text { (HBw 5/250) }\end{array}$ \\
\hline Liga Zamac 8 Comercial - Bruta de Fusão & $121 \mathrm{HB}$ \\
\hline Liga Zamac 8 Comercial - T.T. $150^{\circ} \mathrm{C}$ & $91 \mathrm{HB}$ \\
\hline Liga Zamac 8 Comercial - T.T. $300^{\circ} \mathrm{C}$ & $123 \mathrm{HB}$ \\
\hline Liga Zamac 8 com adição de $8 \% \mathrm{Cu}$ - Bruta de Fusão & $117 \mathrm{HB}$ \\
\hline Liga Zamac 8 com adição de $8 \% \mathrm{Cu}$ - T.T. $150^{\circ} \mathrm{C}$ & $117 \mathrm{HB}$ \\
\hline Liga Zamac 8 com adição de $8 \% \mathrm{Cu}$ - T.T. $300^{\circ} \mathrm{C}$ & $118 \mathrm{HB}$ \\
\hline
\end{tabular}

Pode-se observar que o tratamento térmico realizado com a finalidade de estabilizar a liga via transformação da fase metaestável $\varepsilon\left(\mathrm{CuZn}_{4}\right)$ na fase estável $\tau$ não alterou de forma significativa a dureza para todas as ligas com exceção da liga Zamac 8 comercial tratada a $150{ }^{\circ} \mathrm{C}$ que teve um decréscimo na dureza de cerca de $25 \%$. Quando se correlaciona a dureza com a microestrutura da liga tratada termicamente a $150{ }^{\circ} \mathrm{C}$ com a mesma liga tratada a $300{ }^{\circ} \mathrm{C}$ e com a liga bruta de fusão (FIGURA 10) observa-se que na liga tratada termicamente a $150{ }^{\circ} \mathrm{C}$ o percentual da estrutura eutética presente é baixo, mas ainda não há formação de novas fases/estruturas como se observa na liga tratada a $300 \mathrm{C}$, o que pode ser responsável por sua mais baixa dureza. 


\section{CONCLUSÕES}

A adição de Cobre levou a um aumento no intervalo de solidificação da liga Zamac 8 comercial. Observou-se ainda que o tempo da formação de cada fase/microconstituinte dependeu da quantidade de Cobre na liga. Como consequência, observou-se variação entre as quantidades relativas de cada fase ou microconstituinte presente nas ligas estudadas.

A presença do Cobre na liga de Zamac 8 levou à precipitação da fase metaestável $\mathrm{CuZn}_{4}$, a qual foi observada principalmente nas dendritas de fase primária ricas em Zinco.

A adição de $8 \%$ de Cobre na liga Zamac 8 comercial induziu ao aumento de fase dendrítica primária rica em Zinco e diminuição das estruturas eutética e eutetóide na liga.

Os tratamentos térmicos alteraram a microestrutura, tanto da liga comercial quanto da liga modificada pela adição de Cobre.

Para a liga Zamac 8 comercial tratada termicamente a $150{ }^{\circ} \mathrm{C}$ por $143 \mathrm{~h}$ observou-se ainda algumas partículas da fase $\varepsilon$ presentes nas dendritas da fase primária após tratamento térmico, ao tempo em que a liga tratada termicamente a $300{ }^{\circ} \mathrm{C}$ por $94 \mathrm{~h}$ não. Ao contrário, para a liga Zamac 8 com adição de Cobre tratada termicamente a $150{ }^{\circ} \mathrm{C}$ por $143 \mathrm{~h}$ não se observou partículas da fase $\varepsilon$ nas dendritas da fase primária, enquanto na liga que foi tratada termicamente a $300{ }^{\circ} \mathrm{C}$ por $94 \mathrm{~h}$, sim. No entanto, o mapeamento por EDS mostrou que há cobre em maior concentração na fase primária independente da temperatura e tempo de tratamento térmico, indicando que pode ter havido transformação da fase metaestável $\varepsilon$ na fase estável $\tau$, que também contém cobre. Porém, a comprovação desta transformação não pode ser feita pelas técnicas de caracterização utilizadas neste trabalho, podendo ser confirmada em através da realização de análises de DRX e /ou EBSD, o que pode ser objeto de trabalhos futuros.

Não foi verificado alteração significativa na dureza do material após tratamento térmico, exceto na liga comercial Zamac 8 tratada termicamente a $150{ }^{\circ} \mathrm{C}$ por 94 horas, esta alteração é explicada por sua microestrutura, onde o percentual da estrutura eutética encontrado foi baixo.

Os resultados indicam que tratamentos térmicos podem promover a estabilização da liga Zamac 8 através transformação da fase metaestável $\mathrm{CuZn}_{4}$, conferindo a esta liga maior estabilidade dimensional. Porém, deve ser ressaltado que as temperaturas adequadas para o tratamento térmico são dependentes da composição e microestrutura da liga.

\section{REFERÊNCIAS}

ARES A.E., SCHVEZOV C.E.. The effect os structure on tensile properties of direcionally solidified Zn-based alloys. Journal of Cristal Growth 318, pg. 59-65, 2011. 
ASM METALS HANDBOOK. Casting. Editora ASM. Vol.15, 1992.

ASM METALS HANDBOOK. Metallography And Microstructures. Editora ASM. Vol.9, 1992.

ASTM E10-15, Standard test method for brinell hardness of metallic materials, Pensilvânia, 2015.

COSTA, E.M.; COSTA, C.E.; DALLA VECCHIA, F.; RICK, C.; SCHERER, M.; SANTOS, C.A.; DEDAVID, B.A. Study of the influence of copper and magnesium additions on the microstructure formation of $\mathrm{Zn}-\mathrm{Al}$ hypoeutectic alloys. Journal of Alloys and Compounds, vol. 488, pg. 89-99, 2009.

DORANTES-ROSALES H.J., HIRATA V.M.L., ZHU Y. H.. Decomposition process in a Zn-22wt.\%Al-2wt.\%Cu alloy. Materials Science and Engineering, vol. A27, pg. 366370, 1999.

EL-KAHIR, M.T.A.; DAOUD, A.; ISMAIL, A. Effect of different Al contents on the microstructure, tensile and wear properties of Zn-based alloy. Materials Letters, 58, p. 1754-1760, 2004.

PRASAD B.K.. Effect of microstructure on the sliding wear performance of a Zn-Al-Ni alloy. Wear, vol. 240, pg. 100-112, 2000.

SAVASKAN T., HEKIMOGLU A.. Microstuture and mechanical properties of Zn15AL- based ternary and quaternary alloys. Materials Science and Engineering, vol. A 603,pg. 52-57, 2014.

ZINCO LIGAS, Composição química Liga commercial Zamac 8, 2015.

ZHU, Y.H., LEE, W.B.. Tensile deformation and phase transformation of furnacecooled Zn-Al based alloy. Materials Science and Engineering, vol. A 293, pg. 95-101, 2000 .

ZHU, Y.H., LEE, W.B., YEUNG, C.F, YUE, T.M. EBSD of Zn-rich phases in ZnAl-based alloys. Materials Characterization, vol. 46, pg. 19-23, 2001. 